\title{
O QUE ESTÁ POR VIR?
}

Paulo Vicente dos Santos Alves

A pandemia da COVID-19 aumentou a sensação de imprevisibilidade do ambiente e tem levado muitos gestores a questionar a capacidade de planejamento de médio e longo prazos.

Entretanto, uma pandemia global, assim como outros eventos de alto impacto, faz parte da lista de possibilidades e cenários de qualquer estrategista. Alguns nem consideram que a COVID-19 possa ser considerada como um "cisne negro", isto é, um evento de alto impacto, mas, sim, como uma probabilidade muito baixa ou desconhecida.

O problema parece residir numa forma de pensar no futuro como uma continuidade linear do passado, com crescimento contínuo e com poucas mudanças estruturais.

Existem outras formas de pensar e planejar que levam em conta ciclos, mudanças estruturais e riscos sistêmicos de alto impacto.

Um dos modelos que mais parece ter sido capaz de prever até aqui os eventos das últimas décadas são os ciclos de Kondratieff, ainda que não com 100\% de precisão.

\section{CICLOS DE KONDRATIEFF: TECNOLOGIA NÃO AVANÇA LINEARMENTE}

Nikolai Kondratieff foi um matemático Russo que recebeu uma "encomenda" de Josef Stalin. O ditador queria que ele desenvolvesse um modelo matemático que "provasse" que o comunismo iria vencer e o capitalismo iria acabar. Entretanto, ao estudar a história econômica, Kondratieff chegou à conclusão inversa da desejada por Stalin. Ele percebeu que o que melhor explicava a economia era a tecnologia, mas que esta não avançava linearmente. A cada 50-60 anos, havia uma revolução tecnológica, que ocorria cerca de 2030 anos depois de uma grande crise política, militar e tecnológica. Isto lembrava o que Marx havia analisado, mas era diferente. O capitalismo era de fato intrinsecamente instável, mas ao contrário de entrar em crise e acabar, ele se reinventava através de novas tecnologias, a variável que Marx não havia levado em conta.

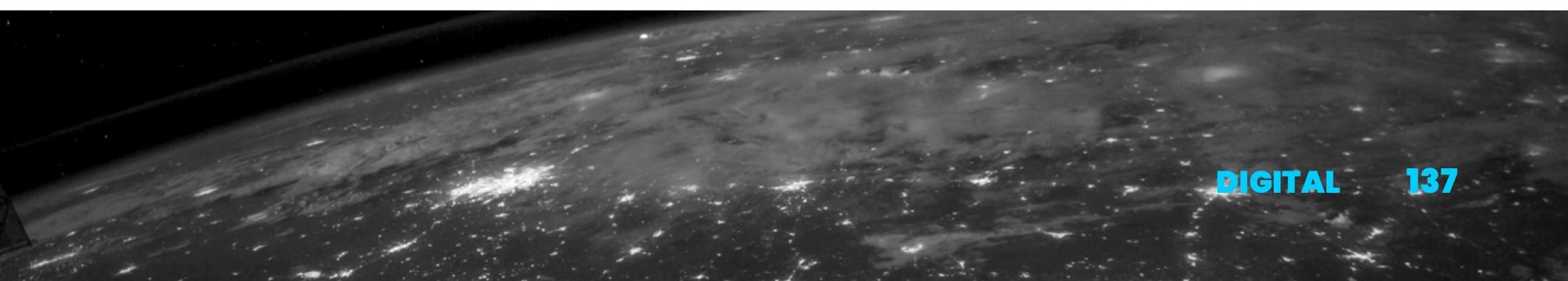


A Tabela 1 mostra o entendimento contemporâneo dos ciclos de Kondratieff, sendo que todos eles terminaram em crises sistêmicas, conforme mostra a Tabela 2.

Tabela 1 - Ciclo de Kondratieff

\begin{tabular}{|c|c|c|}
\hline Ciclo & Período & Descrição \\
\hline lo Ciclo & $1770-1820$ & Mecanização inicial \\
\hline 20 Ciclo & $1820-1870$ & Máquinas a vapor, telégrafo e ferrovias \\
\hline 3o Ciclo & 1870-1930 & $\begin{array}{l}\text { Eletricidade, motor de combustão interna e } \\
\text { engenharia pesada }\end{array}$ \\
\hline 4o Ciclo & 1930-1980 & $\begin{array}{l}\text { Produção em massa, fordismo, energia nuclear } \\
\text { e televisão }\end{array}$ \\
\hline 50 Ciclo & 1980-2030 & Telecomunicações e informática \\
\hline 60 Ciclo & 2030-2080? & ? \\
\hline
\end{tabular}

Fonte: Autor

Tabela 2 - Subfases de crise dos ciclos de Kondratieff

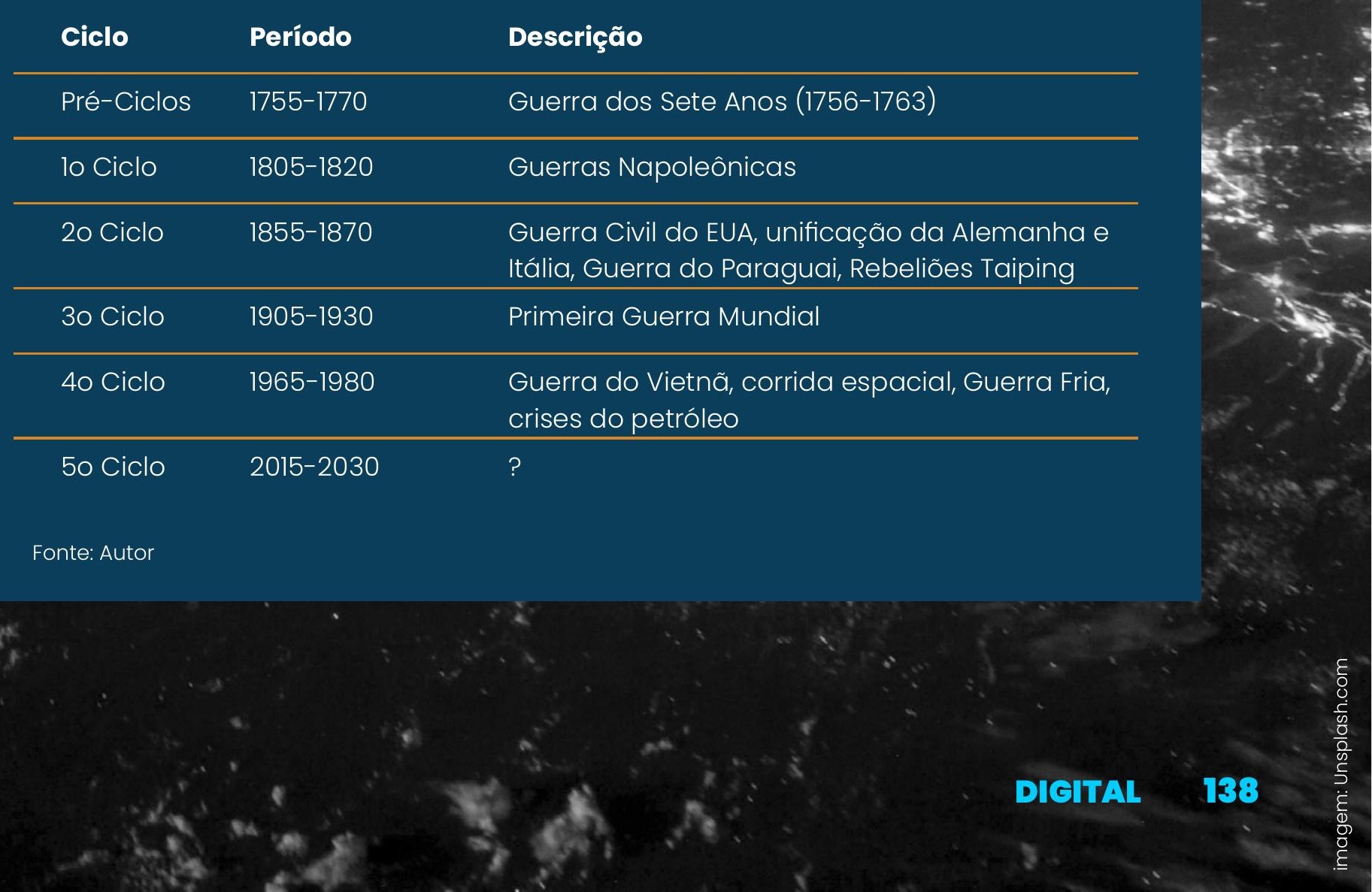


Como se pode ver, o modelo prediz que o período atual seria de uma crise interna do sistema, o que já vinha acontecendo mesmo antes da pandemia. Porém prediz também que, justamente por conta da crise, haverá uma reação com investimentos em tecnologia, criando as bases para uma nova revolução tecnológica.

Assim, o que podemos esperar dos próximos anos é uma crise global, centrada numa nova guerra fria entre EUA e China, que irá estimular o investimento em grande escala em uma gama de novas tecnologias. Iremos então explorar esses dois aspectos deste período de mudança.

\section{UMA NOVA GUERRA FRIA: A TERCEIRA CORRIDA COLONIAL}

A tensão entre EUA e China vai além de diferenças ideológicas e tem raiz no profundo desequilíbrio demográfico e de recursos naturais no planeta. Vivem na Ásia cerca de 4,5 bilhões de pessoas, mais da metade da humanidade. É por isto que a indústria se deslocou em boa parte para lá nos últimos 40 anos, em busca de mão de obra barata.

Porém, embora a Ásia tenha muitos recursos naturais, ela não conta com alimentos e minério em abundância. Mesmo sendo a fonte principal de petróleo, ele é concentrado no Oriente Médio e não uniformemente distribuído pela Ásia.

Isto tem levado, desde a déçde de 80, a und nova corride por recurses naturais, formando uma nova eorrida colonicl aos moldes des duas anteriores, nos séculos XVI e XIX, só que desta vez ela é liderada pelos esićticos, e não pelos europeus.

Entretanto, nós já vimos duas corridas coloniais no passado e sabemos por quais lógicas elas operam. Em um primeiro momento, essa corrida se dá de maneira pacífica, através dos mecanismos de importação e investimento, mas, eventualmente, se atinge um ponto onde a dependência de recursos externos é grande demais e, portanto, se faz necessário reduzir o risco de interrupção.

Nesta altura, a corrida deixa de ser puramente pacífica e são necessários investimentos em infraestrutura militar, tais como bases aeronavais e forças militares capazes de projetar força e garantir a segurança das rotas comerciais. 
Essa fase já começou na África e no sudeste da Ásia. China, Japão e índia estão modernizando e expandindo suas frotas aeronavais. China vem buscando bases no Índico no Paquistão, Myanmar, Ilhas Maldivas, Ilhas Maurício, Vanuatu e Sri Lanka. Recentemente, a China abriu sua primeira base militar permanente fora de seu território, no Djibouti e tem construído bases aeronavais em ilhas, recifes e atóis do Mar do Sul da China, mesmo à revelia da comunidade internacional. A Índia, por sua vez, tem buscado uma base naval com as Ilhas Seicheles.

\section{UMA REVOLUÇÃO TECNOLÓGICA: FOMENTO MILITAR}

Existe uma constante na história que os ciclos de Kondratieff evidencia fortemente. Sempre que ocorre uma corrida militar, ela induz a uma corrida tecnológica.

Isto está transformando o capitalismo. Para entender como, basta "seguir o dinheiro". Sete "eixos" tecnológicos têm recebido grande investimento na última década:

\section{1) Tecnologia espacial}

\section{2) Fontes de energia renovável}

3) Automação (Indústria 4.0)

4) Agricultura de precisão

5) Infraestrutura e logística

6) Transformação digital

\section{7) Melhoria humana (Human Enhancement Technologies - HET)}

Os dois primeiros eixos (espaço e energia) lidam com a redução dos custos de energia e materiais. Isto significa que a matriz energética irá sofrer um grande rebalanceamento no futuro próximo. Ao mesmo tempo, o acesso ao espaço tem tido uma redução dramática de custo devido ao desenvolvimento de foguetes reutilizáveis. A mineração espacial se tornará prática e economicamente viável na década de 2020. 
O terceiro, quarto, quinto e sexto eixos (automação, agricultura, infraestrutura e transformação digital) reduzirão a necessidade de trabalho humano pouco qualificado, enquanto aumentarão a necessidade de mão de obra mais qualificada. Esse processo foi descrito por Schumpeter como "destruição criativa", isto é, milhões de empregos vão ser destruídos e setores da economia irão desaparecer, mas ao mesmo tempo milhões de novos empregos serão criados e novos setores da economia irão surgir. Os termos transformação digital (TD) e Indústria 4.0 foram cunhados para resumir as mudanças nas cadeias produtivas pela adoção destas tecnologias.

O sétimo e último eixo (melhoria humana) irá aumentar a longevidade e qualidade de vida, fazendo com o que o capital intelectual seja ainda mais produtivo e, ao mesmo tempo, irá reduzir o custo de se manter uma força de trabalho produtiva. Podemos dividir essas tecnologias em três linhas: cura de doenças, aumento da longevidade e melhoria humana. O investimento em capital intelectual terá um tempo maior para se pagar, de maneira que será ainda mais atrativo investir em educação continuada. Embora seja discutível o quanto a longevidade da população humana possa ser estendida, um aumento até a faixa dos 100 a 120 anos de idade é bastante provável.

\section{CONCLUSÕES: A BUSCA DE RESILIÊNCIA}

Fica claro que, nos próximos anos, a turbulência no ambiente global vai continuar. Há uma disputa no nível global não só por recursos, mas também por tecnologia, e isto vai causar mudanças estruturais muito fortes que afetarão diversos setores da economia.

O futuro, em um horizonte de 3 a 5 anos, não será linear, mas sim cheio de mudanças, que não irão se completar totalmente.

Isto implica que empresas e organizações terão de se preparar para serem mais resilientes.

Por décadas, o mantra organizacional foi a busca de performance, mas esta busca criou empresas de alto risco e alto retorno, porém vulneráveis a mudanças estruturais e a riscos sistêmicos.

\section{A necessidade nos próximos enosé a de ericir orğ Inizaçêes com médio risco e médio retorno, mais resistentes, robustas e resilientes.}

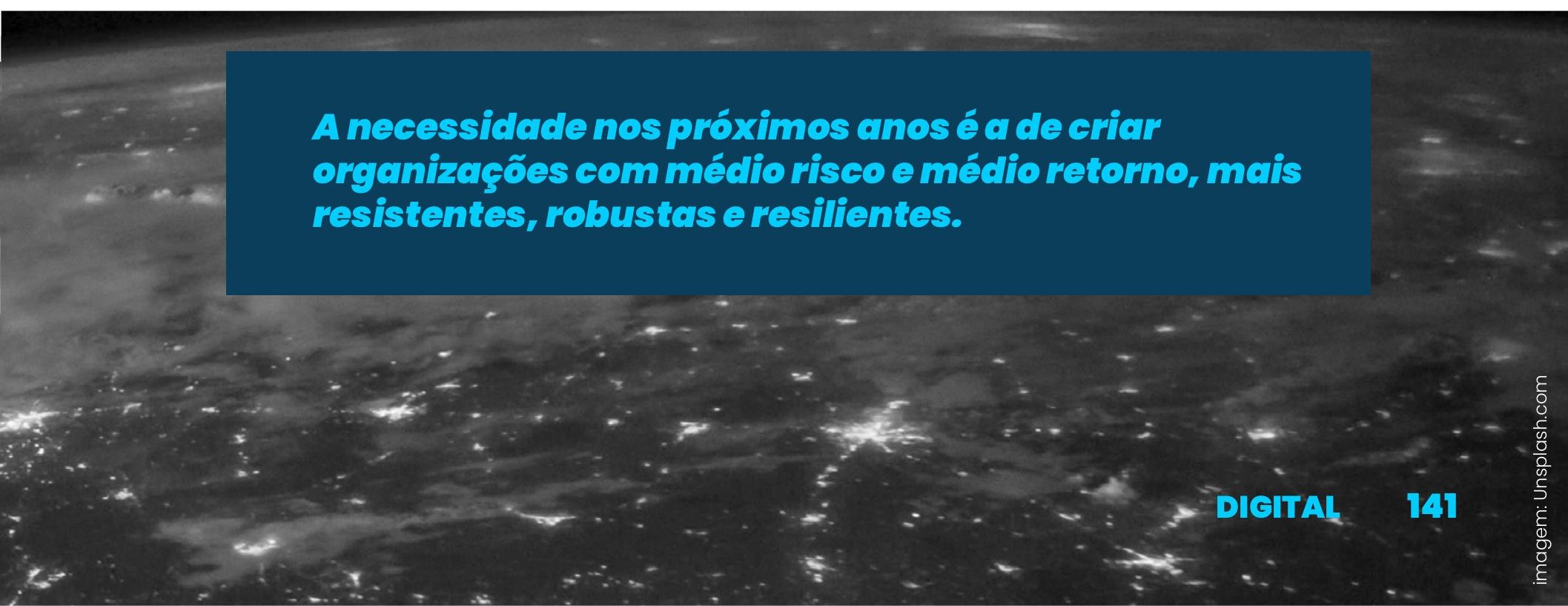


É a hora das "empresas-camelo", não das empresas-unicórnio, foco dos últimos 30 anos. Estamos à beira de um deserto. Precisamos de organizações que sejam capazes de aguentar e de se adaptar às mudanças que estão ocorrendo, e que só irão se completar na década de 2030, quando se anuncia o sexto ciclo de Kondratieff.

As empresas-camelo são as que conseguirão resistir às turbulências extremas nos próximos 5 a 10 anos, quando assistiremos choques geopolíticos, investimentos intensivos em tecnologias, com o florescimento de novas indústrias e tecnologias. São organizações que precisam atuar firmemente nos seguintes eixos para garantir a sua longevidade: caixa na visão de curto prazo, internacionalização, inovação, gestão eficiente das cadeias de suprimentos, ação abrangente de sustentabilidade (fluxo de caixa, sustentabilidade ambiental e social), gestão de pessoas e gestão de marcas.

\section{Paulo Vicente dos Seintos Alves}

Professor Fundação Dom Cabral

Doutor em Administração de Empresas e mestre em Administração Pública, ambos pela FGV. Graduado em Engenharia Elétrica pelo IME. Atualmente é professor da FDC. Foi Sub-Secretário de Planejamento da Secretaria de Estado de Planejamento e Gestão do Rio de Janeiro. Fez parte do Global Colloquium in Participant Centered Learning da Harvard Business School. Foi consultor para a BAT, IADB/BID, Petrobrás, Shell, e o Departamento de Comércio dos Estados Unidos.

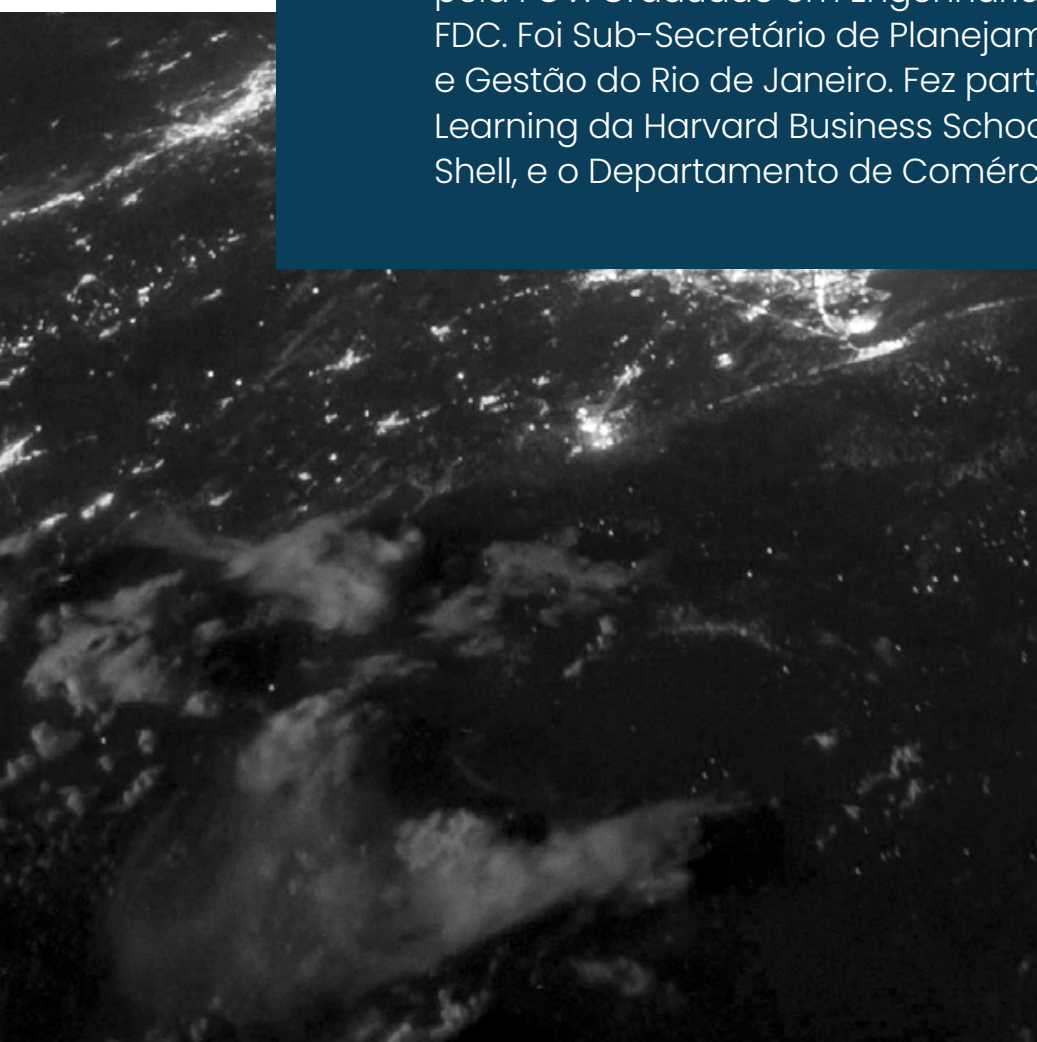

